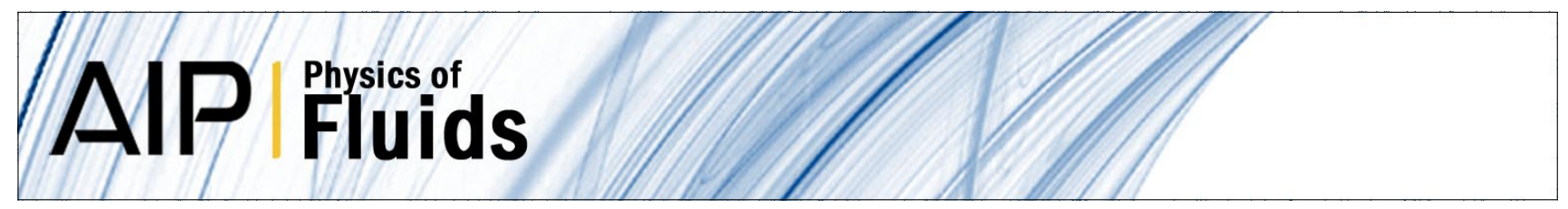

\title{
Shock Tubes in Rarefied Gas Flow Research
}

D. Coles, H. W. Liepmann, A. Roshko, and B. Sturtevant

Citation: Phys. Fluids 12, I-179 (1969); doi: 10.1063/1.1692612

View online: http://dx.doi.org/10.1063/1.1692612

View Table of Contents: http://pof.aip.org/resource/1/PFLDAS/v12/i5

Published by the American Institute of Physics.

\section{Additional information on Phys. Fluids}

Journal Homepage: http://pof.aip.org/

Journal Information: http://pof.aip.org/about/about_the_journal

Top downloads: http://pof.aip.org/features/most_downloaded

Information for Authors: http://pof.aip.org/authors

\section{ADVERTISEMENT}

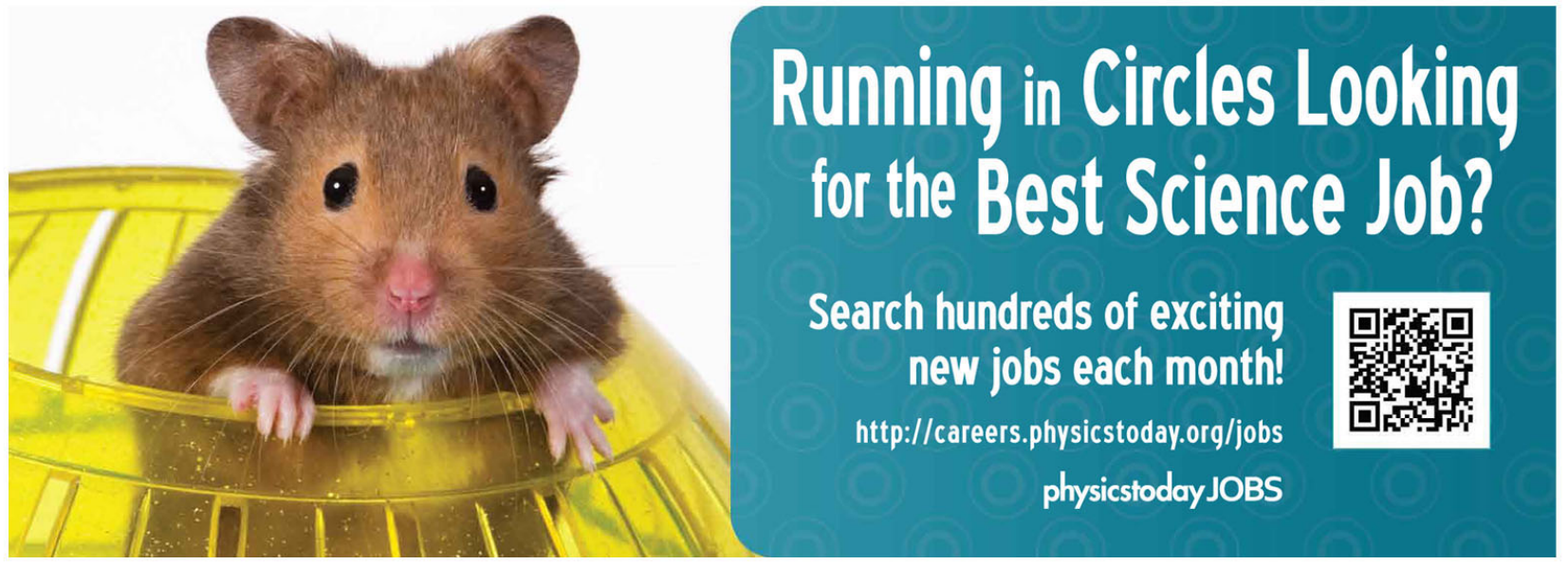




\title{
Shock Tubes in Rarefied Gas Flow Research
}

\author{
D. Coles, H. W. Liepmann, A. Roshko, and B. Sturtevant \\ California Institute of Technology, Pasadena, California
}

The flow within a shock wave is governed by the relaxation times of the molecular degrees of freedom. Advances in shock-tube design and instrumentation in recent years have made it possible to resolve all the relaxation times including the shortest, corresponding to the translational degrees of freedom. The shock tube thus becomes an important tool for critical experiments in the study of the range of applicability of the Navier-Stokes equations and similar approximations and of the character of solutions of the Boltzmann equation. Significant progress has recently been made in the understanding of the most obvious such problem, the flow within a shock in a monatomic gas. Theory and experiment are now in substantial agreement and the over-all process of energy exchange is understood. Progress has been made in problems connected with shock wave reflection from real walls, but a host of others remain to be studied including surface interaction effects. The extension of this type of shock-tube research to more complicated systems, reacting gases, gas mixtures, and the like has begun and some progress can be reported. Recent experimental progress is illustrated by a number of measurements made in the 6 - and 17-in. shock tubes at the California Institute of Technology.

\section{Experimental Consequences of Radiative Shock Structure}

\author{
Angelo James SkaLafuris \\ Bartol Research Foundation, Franklin Institute, Swarthmore, Pennsylvania
}

A shock wave in a three-component gas of hydrogen with radiative transfer is examined. The coupling between fluid and radiation leads to a distortion of the emitted radiation from a Planck spectrum. Lowenergy radiation is stronger than a comparative blackbody emitter, while there is a total absence of radiation above the Lyman continuum due to precursor absorption. We find that the emission may be overestimated by as much as a factor of $10^{5}$ in shock waves of Mach 8 , if a blackbody rather than the true recombination radiation is taken for the radiative source. The electron temperature is much lower than that of the ion, and thus the post-shock relaxation takes a longer time when this temperature separation is considered. Computations of the shock thickness, based upon equal temperatures for the components may be in error by as much as an order of magnitude. Viewed from this analysis, the radiative post-shock temperature spike is merely the rapid decay of a classical temperature jump from a thermodynamic level that has been perturbed by precursor effects. Only the unobservable part of the spectrum induces precursor effects, and this radiation must have a recombination time which is greater than the product of shock velocity and photomean-free-path. Experimentally, the post-shock radiating region is accelerated toward the discontinuity, and thus a Doppler shift measurement of the lines should give the velocity of this region. Stark effect, in general, tends to "redden" the lines, and this requires a judicious choice of materials and speeds for an experiment. A thin absorption core should be removed asymmetrically from the center of the emission line. The separation of emission and absorption peaks should measure the post-shock velocity by Doppler shift and hence give the density. The thickness of the two lines should measure the temperature. ${ }^{1,2}$

\footnotetext{
${ }^{1}$ A. J. Skalafuris, J. Quant. Spectr. Radiative Transfer. 8, 515 (1968).

2 A. J. Skalafuris, Astrophys. Space Sci. 2, 258 (1968).
} 